AJChE 2014, Vol. 14, No. 2, 28 - 37

\title{
Performance Enhancement
}

of Mixed Matrix Membranes through

the Incorporation of Alkanolamines

\section{for $\mathrm{CO}_{2} / \mathrm{CH}_{4}$ Separation}

Rizwan Nasir 1

Hilmi Mukhtar *, 1

Zakaria Man ${ }^{1}$

Maizatul Shima Bt. Shaharun ${ }^{2}$

Mohamad Zailani Abu Bakar ${ }^{3}$

${ }^{1}$ Department of Chemical Engineering, Universiti Teknologi PETRONAS, 32610 Bandar Seri Iskandar, Perak Darul Ridzuan, Malaysia

${ }^{2}$ Department of Fundamental and Applied Science, Universiti Teknologi PETRONAS, 32610 Bandar Seri Iskandar, Perak Darul Ridzuan, Malaysia

${ }^{3}$ School of Chemical Engineering, Universiti Sains Malaysia, 11800 USM, Pulau Pinang, Malaysia

`e-mail : hilmi_mukhtar@petronas.com.my

Diethanolamine (DEA) solution was used in this study to enhance the performance of polyethersulfone (PES) - carbon molecular sieve (CMS) mixed matrix membrane (MMMs). These new amine mixed matrix membranes (A3Ms) were fabricated at room temperature by using fixed concentration of PES, CMS and different concentrations (5, 10 wt. \%) of DEA. The developed mixed matrix membranes were characterized by using field emission scanning electron microscope (FESEM) and thermogravimetric analyser (TGA) in order to investigate the effect of DEA addition on morphology and thermal stability. Gas performance tests were also performed to measure the permeance and selectivity. The characterization results showed that the membranes were thermally stable, dense and non-porous. The gas performance tests showed that the permeance and selectivity of $A 3 \mathrm{Ms}$ is higher than the native PES membrane. $\mathrm{CO}_{2}$ permeance increases with the increase of DEA concentration. Hence it was found that with an addition of $10 \%$ (wt. \%) DEA at a pressure of 2 bars, the $\mathrm{CO}_{2}$ permeance was increased from 50.86 to $127.06 \mathrm{GPU}$ and the $\mathrm{CO}_{2} / \mathrm{CH}_{4}$ selectivity was also increased from 3.08 to 12.30 .

Keywords : Mixed matrix membrane, Alkanolamine solutions, Carbon Dioxide, Permeance. 


\section{INTRODUCTION}

For the separation of gases, membranes have been used for more than 150 years but these were commercially used in 1980 (Baker 2002). When compared to the solvent technology, membrane technology offers more advantages such as the ease of scale up and the potential of having higher energy efficiency. Furthermore, the area required to install the membrane systems is much smaller when compared to solvent systems, hence making retro-fitting easy and cheaper (Xiao, Low et al. 2009).

Separation of gases on industrial scale is accomplished by the distillation, absorption and adsorption; in recent years it increased with the help of membrane technology. Common applications include the separation of $\mathrm{O}_{2} / \mathrm{N}_{2}, \mathrm{CO}_{2} / \mathrm{CH}_{4}, \mathrm{~N}_{2} / \mathrm{CH}_{4}$ and $\mathrm{CO}_{2} / \mathrm{N}_{2}$ among others (Noble and Stern 1995).

The fabrication of gas separation membranes can be carried out by using organic or inorganic materials. The inorganic membranes exhibit the excellent separation performance due to their chemical and thermal stability (SinghGhosal and Koros 2000, Kim, Lee et al. 2004, Park, Kim et al. 2004). Though, the fabrication of these membranes is difficult because these are brittle, and this is the main reason that the fabrication cost of these membranes always increases (Caro, Noack et al. 2000, Vu, Koros et al. 2003, Dong, Li et al. 2013). On the other hand, polymeric membranes have been widely used as they are easy to fabricate and entail low production costs (Powell and Qiao 2006). Polymeric membranes use the sorption diffusion mechanism to separate the gases. In this mechanism, gas molecules are absorbed into the membrane, followed by diffusion (Mulder 1996). Normally, diffusion is enhanced by increasing the volume of free space in the membrane and addition of bulk substitute groups (Powell and Qiao 2006). Since polymeric membranes are believed to be prone to chemical degradation and thermal instability, their applications have been restricted to the areas where hot gases are not involved. Inherent limitations of polymeric membranes and related solutions are described in (Widjojo and Chung 2006, Li 2007, Li, Zhou et al. 2007). In order to overcome the limitations of polymeric and inorganic membranes, an approach of combining both polymeric membranes and inorganic particles has been identified to fabricate the membranes with superior separation characteristics. These are known as mixedmatrix membranes (MMMs) (Chung, Jiang et al. 2007, Dong, Li et al. 2013). MMMs with hybrid physiognomies were developed as a substitute approach for above mentioned limitations. They showed the excellent gas separation properties of inorganic materials and combine desirable mechanical properties with the economical processing capacity of polymers (Moore, Mahajan et al. 2004, Nasir, Mukhtar et al. 2013).

Two types of polymers are being used to fabricate the mixed matrix membranes a) rubbery polymer and b) glassy polymers. But most studies are focused on the glassy polymers such as cellulose acetate (CA), polysulfone (PSU), polyimide $(\mathrm{PI})$, polyamide $(\mathrm{PA})$, and polyethersulfone (PES) etc. which exhibits the high 
separation performance, lying much closer to the upper-bound limit. Many studies report that the MMMs are good choice for the $\mathrm{CO}_{2} / \mathrm{CH}_{4}$ separation (Bushell, Attfield et al. 2013, Galve, Sieffert et al. 2013, Magueijo, Anderson et al. 2013, Rostamizadeh, Rezakazemi et al. 2013). But still there are some challenges in MMM preparation chain rigidification, pore blockage, low adhesion and the dispersion of particles within the organic matrix (e.g., agglomeration or sedimentation of particles) (Dong, Li et al. 2013).

Alkanolamine solutions like monoethanolamine (MEA), diethanolamine (DEA) (Guo and Ghalambor 2005), methyldiethanolamine (MDEA) etc., has also been used for carbon dioxide removal (Speight 2007), and this technology is well matured (Olajire 2010). Though it has extensive commercial use, this technique has also some limitations like low $\mathrm{CO}_{2}$ loading capacity, high corrosion rate, high energy consumption, (Olajire 2010) and high solution circulation rate and also solution degradation (Liu, Song et al. 2010).

Therefore, the purpose of this work is to combine the facilitated transport mechanism of diethanolamine (DEA) with the molecular sieving mechanism of carbon molecular sieve (CMS) to improve the $\mathrm{CO}_{2} / \mathrm{CH}_{4}$ separation performance of MMMs. To our best knowledge, still there is no academic literature available on blending of DEA with CMS to fabricate the mixed matrix membrane for gas separation. CMS with fixed weight ratio was used as the dispersed phase in this work because of its suitable pore size for
$\mathrm{CO}_{2} / \mathrm{CH}_{4}$ separation. DEA with different concentration was used as alkanolamine solution for its favourable reaction kinetics with acid gases and also because of its stability when regenerated. Polyethersulfone (PES) was chosen as the continuous polymer matrix because of its appropriate $\mathrm{T}_{g}$ of $225^{\circ} \mathrm{C}$ and various applications in gas separation (Chiou, Maeda et al. 1987, Li, Chung et al. 2007). The developed membranes were characterized and gas permeation rates of flat sheet dense $\mathrm{A} 3 \mathrm{Ms}$ and pure PES membranes were measured as a function of amine loading.

\section{MATERIALS AND METHODS}

\section{Material Selection}

Polyethersulfone (ULTRASON E 6020P) was supplied by BASF ${ }^{\circledR}$ Chemicals Germany. The polymer was dried overnight in an oven at $100^{\circ} \mathrm{C}$. 1-methyl-2 pyrrolidone (NMP) from Merck was used as the solvent due to its low toxicity. Diethanolamine (DEA) also from Merck was chosen as alkanolamine solution and carrier to facilitate the $\mathrm{CO}_{2}$ transport. Carbon molecular sieve (CMS) was supplied by Japan Enviro Chemical (Takeda). CMS was used as inorganic filler for the development of mixed matrix membrane. CMS particles were also dried in an oven overnight at $100^{\circ} \mathrm{C}$ to remove the absorbed moisture.

\section{Membrane Preparation}

The 20 wt. \% CMS powder was added in NMP, and the mixture was stirred for 15 minutes. To effectively disperse the CMS particles, CMS-NMP solution was 
Table 1. Dope Solution Composition and Thickness of Developed Membranes

\begin{tabular}{ccccc}
\hline Membrane Name & $\begin{array}{c}\text { PES } \\
\text { (wt. \%) }\end{array}$ & $\begin{array}{c}\text { CMS } \\
\text { (wt. \%) }\end{array}$ & $\begin{array}{c}\text { DEA } \\
\text { (wt. \%) }\end{array}$ & $\begin{array}{c}\text { Thickness } \\
(\boldsymbol{\mu m})\end{array}$ \\
\hline M-1 & 20 & - & - & 64.44 \\
M-2 & 20 & 20 & - & 51.37 \\
M-3 & 20 & 20 & 5 & 54.63 \\
M-4 & 20 & 20 & 10 & 32.83 \\
\hline
\end{tabular}

ultrasonicated for 30 min at a frequency of $100 \mathrm{~Hz}$. Subsequent to that, $10 \%$ of total polymer and a specified quantity of DEA were also added into the solution, and the solution was again stirred for 1 hour at room temperature. In the next step the leftover polymer was added in the solution and once again it was stirred for 24 hours at ambient conditions. After obtaining a homogenous viscous solution, it was degassed to remove air bubbles. Then it was casted on a glass plate by adjusting the knife gap at 180 microns. The casted membranes were dried in an oven at $160^{\circ} \mathrm{C}$ for 24 hours. The developed mixed matrix membranes were cooled out naturally at room temperature and were kept in desiccators for gas performance test and characterization. Table 1 shows the composition of dope solution and thickness of all developed membranes.

\section{Characterization of Membranes}

The properties of developed membranes were investigated by using TGA (Perkin Elmer, TGA 4000) and Variable Pressure Field Emission Scanning Electron Microscope (VPFESEM, Zeiss Supra55 VP). FESEM images of membranes were taken after being dried in a oven. The thermal behaviour of membrane was analysed by using TGA. The temperature range from 30
${ }^{\circ} \mathrm{C}$ to $800{ }^{\circ} \mathrm{C}$, and the heating rate was 10 ${ }^{\circ} \mathrm{C} / \mathrm{min}$.

\section{Gas Performance Test}

The resulting membranes were tested with a feed gas that was a pure gas of $\mathrm{CO}_{2}$ and $\mathrm{CH}_{4}$. The effective area of the tested membrane is $17.35 \mathrm{~cm}^{2}$. The pure gas permeance properties were evaluated by a variable-pressure constant-volume method at $25{ }^{\circ} \mathrm{C}$. The permeance of the gas was calculated by using following equation:

$\frac{P_{i}}{L}=\frac{N_{i}}{\Delta P_{i}}$

The gas selectivity $(\alpha)$ was calculated by following equation:

$$
\alpha_{i / j}=\frac{P_{i}}{P_{j}}=\frac{\frac{P_{i}}{L}}{\frac{P_{j}}{L}}
$$

\section{RESULTS AND DISCUSSION}

\section{Morphological Analysis}

Figure 1 shows the FESEM crosssectional morphology of $M-1, M-2, M-3$, and $\mathrm{M}-4$ membranes with fixed loading (20 wt. \%) of CMS and different concentration of DEA. The pure PES (M-1) 
(a)

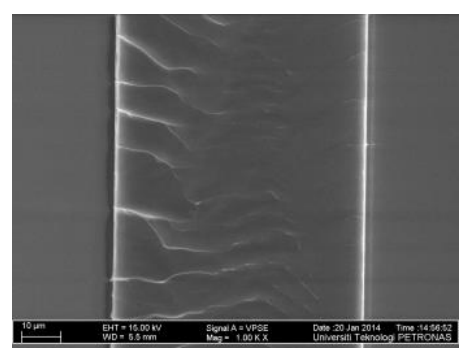

(c)

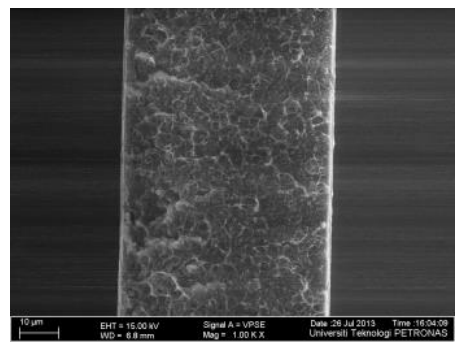

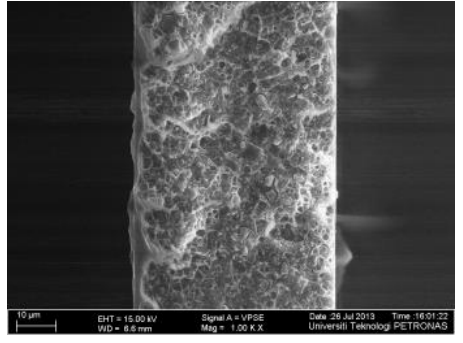

(b)

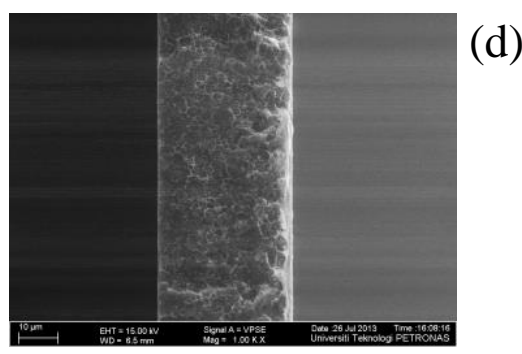

Fig.1 : FE SEM Micrographs of a) $M-1$, b) $M-2$, c) $M-3$ and d) $M-4$ Membranes (Magnification 1000X)

membrane shows the good interaction of polymer with solvent. This membrane exhibits the dense and smooth structure. There are no voids present. The PES-CMS membrane (M-2) shows that CMS particles are dispersed in polymer matrix. The $\mathrm{M}-2$ also has dense and non-porous structure. In this membrane, there is some agglomeration of CMS particles. It is also observed that some CMS particles experienced the sieve in cage. The PESCMS-5\% DEA (M-3) and PES-CMS-10\% DEA (M-4) membranes show the smooth, homogenous, and dense structure. In these membranes CMS particles are dispersed uniformly in the polymer matrix and there is no evidence of phase separation. No interfacial gaps are detected between the polymeric phase and the CMS particle phase, indicating good compatibility between polymer, CMS, and amine. It can generally be concluded that no void formation exists and no agglomeration took place with the addition of DEA. Table 1 shows the thickness of all developed membranes.

\section{Thermogravimetric Analysis (TGA)}

Figure 2 shows the TGA thermograms of $M-1, M-2, M-3$, and $M-4$ membranes. According to Figure 2, M-1 membrane shows the two weight loss curves at $202^{\circ} \mathrm{C}$ and $454.44^{\circ} \mathrm{C}$, which is the result of presence of solvent and degradation of polymer respectively (Krishnan, Kim et al. 2006, Han, Lee et al. 2010). The membrane M-2 also shows two curves. Due to the addition of CMS particles the degradation temperature of polymer increased. The $\mathrm{M}$ 3 and M-4 membranes show the same trends like $\mathrm{M}-1$ and $\mathrm{M}-2$ membranes. The first weight loss indicates the presence of amine. The boiling points of amine and solvent are closer to each other. But due to the addition of amine the temperature was increased from around $202^{\circ} \mathrm{C}$ to $233^{\circ} \mathrm{C}$. This shows the presence of amine 


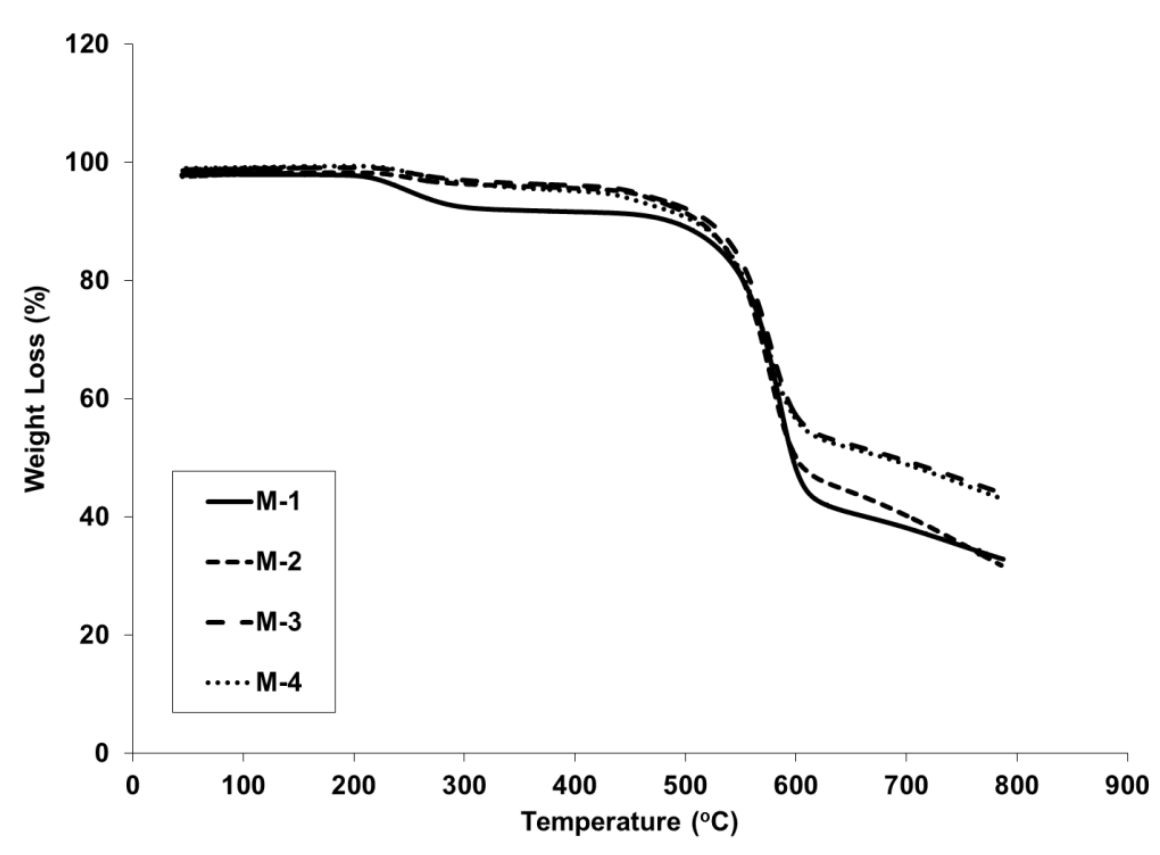

Fig.2 : TGA analysis of $M-1, M-2, M-3$ and $M-4$ Membranes

in the membranes. The residue of $\mathrm{M}-3$ and M-4 was increased by the addition of DEA [36]. This indicates that the DEA has attached to the polymer matrix. So we can conclude that the presence of DEA \& CMS make membranes more stable.

\section{Gas Performance Test}

As stated before, the addition of the DEA and CMS into the casting solution results in a denser non-porous membrane. The $\mathrm{CO}_{2}$ permeance and $\mathrm{CO}_{2} / \mathrm{CH}_{4}$ selectivity can change due to carbonaceous porous solids (CMS) that contains relatively wide opening with constricted apertures that approach the molecular dimensions of the diffusing gas molecules (Ismail and David 2001) and the addition of DEA also facilitate the $\mathrm{CO}_{2}$ transport through membrane. Figures 3 and 4, respectively, describe the effects of the feed pressure on $\mathrm{CO}_{2}$ permeance, and the behavior of $\mathrm{CO}_{2} / \mathrm{CH}_{4}$ selectivity of membranes against feed pressure. As demonstrated in Figures 3 and 4, the membrane containing a higher content of the DEA showed a higher $\mathrm{CO}_{2}$ permeance and a higher $\mathrm{CO}_{2} / \mathrm{CH}_{4}$ selectivity. The increase in $\mathrm{CO}_{2}$ permeance as well as $\mathrm{CO}_{2} / \mathrm{CH}_{4}$ selectivity with the increase in the DEA content is explained by more contribution of the facilitated transport mechanism to the total $\mathrm{CO}_{2}$ permeance. There is no facilitated transport for the permeation of $\mathrm{CH}_{4}$, so the main effect of the higher concentration of the DEA for $\mathrm{CH}_{4}$ permeation is a denser membrane structure and so less $\mathrm{CH}_{4}$ permeance (Ben Hamouda, Nguyen et al. 2010, Saedi, Madaeni et al. 2013).

The $\mathrm{CO}_{2}$ permeance for $\mathrm{M}-3$ and $\mathrm{M}-4$ membranes is higher than pure $\mathrm{M}-1$ and M-2 membranes in all studied pressure ranges because of the amalgamation of facilitated mechanism in $\mathrm{CO}_{2}$ transport. There is no facilitated transport mechanism for $\mathrm{CH}_{4}$ in the $\mathrm{M}-3$ and $\mathrm{M} 4$ membranes. 


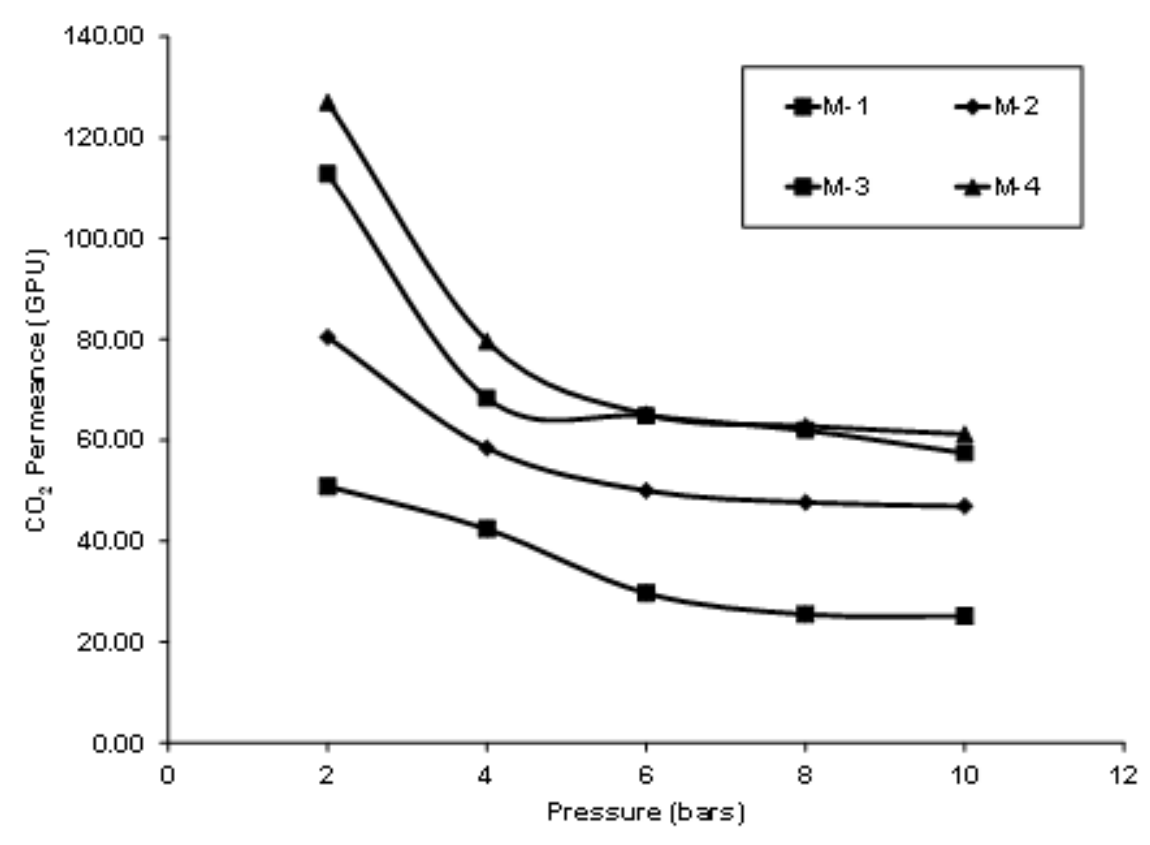

Fig.3 : $\mathrm{CO}_{2}$ Permeance w.r.t. Pressure of $M-1, M-2, M-3$ and $M-4$ Membranes

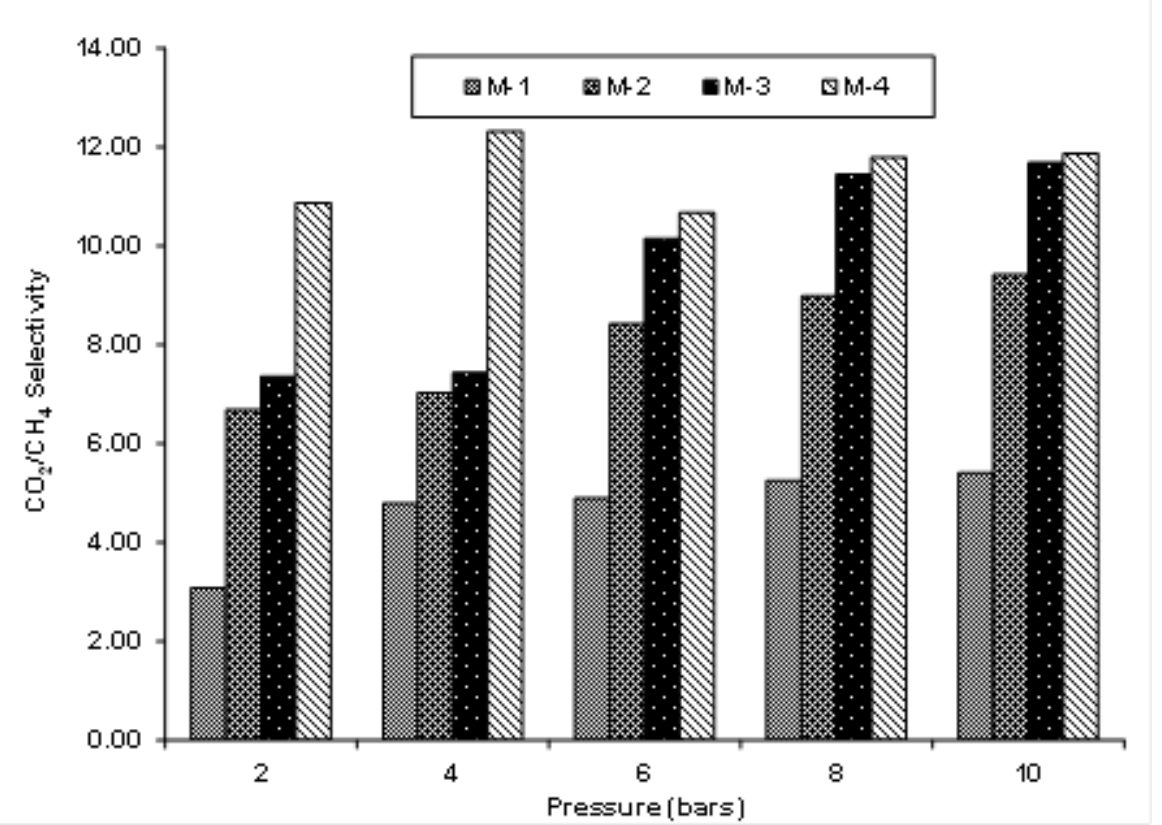

Fig.4 : $\mathrm{CO}_{2} / \mathrm{CH}_{4}$ Selectivity w.r.t. Pressure of $\mathrm{M}-1, \mathrm{M}-2, \mathrm{M}-3$ and $\mathrm{M}-4$ Membranes

\section{CONCLUSIONS}

In this study, we prepared a mixed matrix membrane by adding the DEA as a facilitated carrier and CMS particles as inorganic filler. Due to the facilitated transport mechanism and CMS homogenous distribution, the higher $\mathrm{CO}_{2}$ permeance was achieved. The lower $\mathrm{CH}_{4}$ permeance which resulted from a denser membrane structure, less affinity with DEA and large kinematic diameter of CMS improved the membrane performance including the $\mathrm{CO}_{2} / \mathrm{CH}_{4}$ selectivity and the 
$\mathrm{CO}_{2}$ permeance. The behavior of the developed membranes against the change in the feed pressure was better than that of the pure PES membrane. Further increase is possible by increasing the loading of CMS and DEA concentration.

\section{ACKNOWLEDGMENT}

The authors thankfully acknowledge the financial support and facilities provided by Ministry of Science, Technology and Innovation (MOSTI) e - Science Fund 0153AB-B57 and Universiti Teknologi PETRONAS Malaysia.

\section{REFERENCES}

1. Baker, R. W. (2002). Future directions of membrane gas separation technology, Ind. Eng. Chem. Res., 41(6), 1393.

2. Ben Hamouda, S., Q. T. Nguyen, D. Langevin and S. Roudesli (2010). Poly(vinylalcohol)/poly(ethyleneglycol) /poly(ethyleneimine) blend membranes - structure and $\mathrm{CO}_{2}$ facilitated transport, C. R. Chim., 13(3), 372.

3. Bushell, A. F., M. P. Attfield, C. R. Mason, P. M. Budd, Y. Yampolskii, L. Starannikova, A. Rebrov, F. Bazzarelli, P. Bernardo, J. Carolus Jansen, M. Lanč, K. Friess, V. Shantarovich, V. Gustov and V. Isaeva (2013). Gas permeation parameters of mixed matrix membranes based on the polymer of intrinsic microporosity PIM-1 and the zeolitic imidazolate framework ZIF-8, J. Membr. Sci., 427(0), 48.
4. Caro, J., M. Noack, P. Kölsch and R. Schäfer (2000). Zeolite membranes state of their development and perspective, Micropor. And Mesopor. Mater., 38(1), 3.

5. Chiou, J., Y. Maeda and D. Paul (1987). Gas permeation in polyethersulfone, $J$. Appl. Polym. Sci., 33(5), 1823.

6. Chung, T. S., L. Y. Jiang, Y. Li and S. Kulprathipanja (2007). Mixed matrix membranes (MMMs) comprising organic polymers with dispersed inorganic fillers for gas separation, Prog. Polym. Sci., 32(4), 483.

7. Dong, G., H. Li and V. Chen (2013). Challenges and opportunities for mixed-matrix membranes for gas separation, J. Mater. Chem., A 1(15), 4610.

8. Galve, A., D. Sieffert, C. Staudt, M. Ferrando, C. Güell, C. Téllez and J. Coronas (2013). Combination of ordered mesoporous silica MCM-41 and layered titanosilicate JDF-L1 fillers for 6FDA-based copolyimide mixed matrix membranes, J. Membr. Sci., 431(0), 163.

9. Guo, B. and A. Ghalambor (2005). Natural gas engineering handbook, Gulf publishing company, Houston, TX. 10. Han, J., W. Lee, J. M. Choi, R. Patel and B.-R. Min (2010). Characterization of polyethersulfone/polyimide blend membranes prepared by a dry/wet phase inversion: Precipitation kinetics, morphology and gas separation, J. Membr. Sci., 351(1-2), 141.

11. Ismail, A. F. and L. David (2001). A review on the latest development of carbon membranes for gas separation, 
J. Membr. Sci., 193(1), 1.

12. Kim, Y. K., J. M. Lee, H. B. Park and Y. M. Lee (2004). The gas separation properties of carbon molecular sieve membranes derived from polyimides having carboxylic acid groups, J. Membr. Sci., 235(1-2), 139.

13. Krishnan, N. N., H. J. Kim, M. Prasanna, E. Cho, E. M. Shin, S. Y. Lee, I. H. Oh, S. A. Hong and T. H. Lim (2006). Synthesis and characterization of sulfonated poly(ether sulfone) copolymer membranes for fuel cell applications, J. Power Sources, 158(2), 1246.

14. Li, K. (2007). Ceramic membranes for separation and reaction, John Wiley $\&$ Sons Ltd., West Sussex, England.

15. Li, Y., T.-S. Chung and S. Kulprathipanja (2007). Novel Ag+-zeolite/polymer mixed matrix membranes with a high $\mathrm{CO}_{2} / \mathrm{CH}_{4}$ selectivity, AIChE J., 53(3), 610.

16. Li, Y., H. Zhou, G. Zhu, J. Liu and W. Yang (2007). Hydrothermal stability of LTA zeolite membranes in pervaporation, J. Membr. Sci., 297(1), 10.

17. Liu, K., C. Song and V. Subramani (2010). Hydrogen and syngas production and purification technologies, Wiley Online Library, Hoboken, NJ.

18. Magueijo, V. M., L. G. Anderson, A. J. Fletcher and S. J. Shilton (2013). Polysulfone mixed matrix gas separation hollow fibre membranes filled with polymer and carbon xerogels, Chem. Eng. Sci., 92(0), 13.

19. Moore, T. T., R. Mahajan, D. Q. Vu and W. J. Koros (2004). Hybrid membrane materials comprising organic polymers with rigid dispersed phases, AIChE J., 50(2), 311.

20. Mulder, M. (1996). Basic principles of membrane technology, Springer.

21. Nasir, R., H. Mukhtar, Z. Man and D. F. Mohshim (2013). Material Advancements in Fabrication of Mixed-Matrix Membranes, Chem. Eng. Technol., 36(5), 717.

22. Noble, R. D. and S. A. Stern (1995). Membrane separations technology: principles and applications, Elsevier.

23. Olajire, A. A. (2010). $\mathrm{CO}_{2}$ capture and separation technologies for end-ofpipe applications - A review, Energy, 35(6), 2610.

24. Park, H. B., Y. K. Kim, J. M. Lee, S. Y. Lee and Y. M. Lee (2004). Relationship between chemical structure of aromatic polyimides and gas permeation properties of their carbon molecular sieve membranes, J. Membr. Sci., 229(1), 117.

25. Powell, C. E. and G. G. Qiao (2006). Polymeric $\mathrm{CO}_{2} / \mathrm{N}_{2}$ gas separation membranes for the capture of carbon dioxide from power plant flue gases, $J$. Membr. Sci., 279(1-2), 1.

26. Rostamizadeh, M., M. Rezakazemi, K. Shahidi and T. Mohammadi (2013). Gas permeation through $\mathrm{H}_{2}$-selective mixed matrix membranes: Experimental and neural network modeling, Int. J. Hydro.Ener., 38(2), 1128.

27. Saedi, S., S. S. Madaeni, F. Seidi, A. A. Shamsabadi and S. Laki (2013). Synthesis and application of a novel Amino-Starch derivative as a new polymeric additive for fixed facilitated transport of carbon dioxide through an 
asymmetric polyethersulfone (PES) membrane, Int. J. Greenhouse Gas Contr., 19(0), 126.

28. Singh-Ghosal, A. and W. Koros (2000). Air separation properties of flat sheet homogeneous pyrolytic carbon membranes, J. Membr. Sci., 174(2), 177.

29. Speight, J. G. (2007). Natural Gas: $A$ Basic Handbook, Gulf Publishing Company.

30. Vu, D. Q., W. J. Koros and S. J. Miller (2003). Mixed matrix membranes using carbon molecular sieves: I. Preparation and experimental results, J. Membr. Sci., 211(2), 311-334.
31. Widjojo, N. and T. S. Chung (2006). Thickness and air gap dependence of macrovoid evolution in phaseinversion asymmetric hollow fiber membranes, Ind. Eng. Chem. Res., 45(22), 7618.

32. Xiao, Y., B. T. Low, S. S. Hosseini, T. S. Chung and D. R. Paul (2009). The strategies of molecular architecture and modification of polyimide-based membranes for $\mathrm{CO}_{2}$ removal from natural gas-A review, Prog. Polym. Sci., 34(6), 561. 